Research Article

\title{
Triaxial Compressive Failure Characteristics and Constitutive Model Study of Jurassic-Cretaceous Weakly Cemented Sandstone
}

\author{
Jinlong Cai ${ }^{1}$ and Wei Zou $\mathbb{D}^{2}$ \\ ${ }^{1}$ School of Architecture and Civil Engineering, West Anhui University, Luan, Anhui 237012, China \\ ${ }^{2}$ School of Economics and Management, Lu'an Vocational College, Luan, Anhui 237158, China \\ Correspondence should be addressed to Wei Zou; 115381108@qq.com
}

Received 6 September 2020; Revised 8 November 2020; Accepted 21 November 2020; Published 24 December 2020

Academic Editor: Zhijie Wen

Copyright (c) 2020 Jinlong Cai and Wei Zou. This is an open access article distributed under the Creative Commons Attribution License, which permits unrestricted use, distribution, and reproduction in any medium, provided the original work is properly cited.

A conventional triaxial compression test of Jurassic-Cretaceous typical weakly consolidated sandstone from a mining area in Ordos, China, was conducted using an MTS816 tester. Results showed that, before the peak, the rock had a distinct yield stage. When the specimen reached its peak strength, the strength decreased rapidly and showed an obvious brittle failure. When the confining pressure was increased to $15 \mathrm{MPa}$, the decrease of strength was slow and the rock tended toward ductile failure. With the increase of confining pressure, the cyclic strain initially increased slightly, whereas the volumetric strain increased greatly and the rock sample was in a compression state. When the load reached a critical value, the curve was reversely bent, resulting in volume expansion, whereas the peak strength, residual strength, and elastic modulus increased with confining pressure, and Poisson's ratio decreased with the confining pressure. In the model based on macroscopic failure rock, the expression of the relationship between fracture angle and confining pressure provided a solid theoretical basis for the direction and failure mode of the macroscopic crack. Based on the rock strength theory and Weibull random distribution assumption of rock element strength, the damage variable correction coefficient was introduced when the residual strength was considered. Then, the mathematical expression of the 3D damage statistical constitutive model was established. Finally, the theoretical curve of the established constitutive model was compared with the triaxial test curve, which showed a high degree of coincidence.

\section{Test Profile}

1.1. Rock Sampling and Microscopic Characteristics. In the production and construction of the Ordos mining area in China, Jurassic-Cretaceous strata are mostly weakly cemented rock masses, which are typically characterized by low strength, poor cementation, easy weathering, argillization during exposure to water, and low uniaxial compression strength and tensile strength. As a result of these typical engineering mechanical properties, coring from the weakly cemented rocks becomes difficult; thus, the coring rate is extremely low, and acquiring complex mechanical properties through the laboratory test is difficult $[1,2]$.

Various safety accidents, such as roof caving, collapse, and support failure, usually occur in soft rock roadways. Weakly cemented rocks have gradually attracted close attention from scientific researchers because of their special mechanical properties. For instance, Li et al. [3] conducted mineral composition analysis and microstructure analysis using an X-ray diffractometer and electron microscope scanner. Chen [4] experimented on Jurassic and Cretaceous argillaceous sandstones in northern Xinjiang and pointed out that the sandstones mainly experienced circumferential deformation and volume expansion under low confining pressure. As the confining pressure increased, the failure mode gradually shifted from volume expansion to volume compression. When exposed to water, both types of rocks exhibited an improvement in ductile plasticity and strainsoftening characteristics. By integrating 3D laser scanning with geographic information system technique in their analysis, Song et al. [5, 6] found that the reduction of shear strength was correlated with the cohesiveness of skeleton particles and the softening characteristic of cementing material after absorbing water was a key deciding factor in 
the fracture appearance induced by shear failure. Through field research, theoretical analysis, and laboratory test, Sun et al. [7] compared rocks in an eastern mining area and weakly cemented rocks in a western mining area and obtained burial depth-dependent change features of elasticity modulus, compressive strength, tensile strength, cohesion, internal friction angle, and Poisson's ratio of the rocks. Through a uniaxial compression test of weakly cemented argillaceous sandstones under natural and dry states, Li et al. [8] observed that the mechanical properties of dry rock samples were approximately identical to those of hard brittle rock; for moisture-containing rock samples, elasticity modulus and postpeak residual stress deteriorated to different degrees, but lateral swelling deformation increased. Taking weakly cemented sandstones in Honghe and Xiaojihan coalmines as study objects, Wang et al. [9-11] conducted uniaxial and conventional triaxial tests, analyzed and described the compression change before and after the yield point using two-part Hooke's model and statistical damage model, and constructed their constitutive models. Zhao $[12,13]$ investigated the mechanical properties and damage characteristics of weakly cemented mudstone through a triaxial test and constructed a statistical constitutive model of the damage. Meng et al. [14, 15] used weakly cemented rock masses to establish the corresponding yield criterion and construct the constitutive models of extremely weakly cemented rock masses with different moisture contents. To sum up, previous studies on weakly cemented rocks have achieved important results with emphasis on microstructural morphology, rock deformation behavior, and constitutive relation, but few studies have explored the failure characteristics of Cretaceous-Jurassic sandstone under triaxial compression conditions and the constitutive relation considering the correction of residual strength.

To explore the mechanical properties of CretaceousJurassic weakly cemented sandstones and reveal the rock failure characteristics, the present study analyzed samples of typical weakly cemented sandstones from a mine through scanning electron microscopy (SEM) and mechanical property test. The failure characteristics were examined, based on which the reasonable constitutive damage relations were established to provide a basis for roadway support design in the Ordos mining area.

The rock samples were collected from an inspection hole that was 569.0-630.5 $\mathrm{m}$ deep, and the exposed formations were lower Quaternary and Jurassic Zhidan Group, middle Jurassic Zhiluo Formation, and middle-lower Jurassic Yan'an Group. According to the coring results formed through voidtype argillaceous cementation, the sandstones of different size fractions were loose and fragile; thus, they were unsuitable for remote transportation and coring. Based on the mechanical strength test results of rocks in this section, the main associate inspection hole was 606.87-607.67 $\mathrm{m}$ deep. The medium-fine sandstones within $569.35-575.45 \mathrm{~m}$ were classified as semihard rocks, which had a uniaxial compressive strength of 20.2-35.8 MPa; these materials were used as triaxial compression test samples in the present study. Their microstructures were observed through SEM and X-ray diffraction (XRD) analysis as shown in Figure 1.
As presented in Figures 1(a) and 1(b), these types of rocks were piled up with nonuniform grain size and distinct edges and corners, different sizes of pores were formed, small particulate matters were embedded near the pores, and a certain amount of nonuniform flocculent cement classified as clay minerals adhered to the particle surface. With poor rounding and separation properties, the rocks were mainly formed by void-type cementation, along with base-type cementation, and most of the cement types were clay minerals. The XRD analysis was performed on four rock samples, which had quartz, feldspar, illite, kaolinite, and chlorite as main mineral components. Quartz accounted for 25\%-38\% (average percentage: $30.75 \%$ ) of the contents and kaolinite accounted for $30 \%-50 \%$ (average percentage: 41.25\%) (Figure 1(d)).

1.2. Test Conditions and Test Plan. US MTS816 full-automatic triaxial rock test system introduced by Anhui University was used to conduct the triaxial compression failure test under various confining pressures (Figure 2). The maximum axial load that could be applied by the equipment was $1,000 \mathrm{kN}$, the maximum confining pressure was $60 \mathrm{MPa}$, and the maximum axial and transverse deformations were $20 \mathrm{~mm}$ and $5 \mathrm{~mm}$, respectively. The standard samples were prepared in accordance with Specifications for Rock Tests in Water Conservancy and Hydroelectric Engineering (SL2642001). The size of each rock sample was $50 \mathrm{~mm}$ (diameter) $\times$ $100 \mathrm{~mm}$ (height), and the nonparallelism at the two ends of each sample was less than $0.05 \mathrm{~mm}$. The samples were selected and grouped according to longitudinal wave velocity to guarantee their uniformity. First, each rock sample was placed between upper and lower cushion blocks, the size of which was basically identical to the sample diameter. Each sample was then wrapped using an imported double-layer latex cover together with upper and lower cushion blocks and then ironed out with a hot-air blower. The upper and lower ends of the latex cover were tightened using iron wires to discourage high confining pressure from squeezing out the latex cover under sample failure and prevent hydraulic oil from entering the latex cover, as these conditions would influence the test results.

The axial and confining pressures were applied at a rate of $0.05 \mathrm{MPa} / \mathrm{s}$ to present value in the initial phase, and the confining pressure was maintained during the test process. The displacement control mode was adopted in axial direction, the upper limit of compressive displacement was set, and the axial load was applied at a rate of $0.005 \mathrm{~mm} / \mathrm{s}$ until the sample underwent failure. Several confining pressures used in this test corresponded to the supporting forces provided in practical engineering, that is, $0,5,10$, and $15 \mathrm{MPa}$. Each group had three test blocks.

\section{Test Result Analysis of Weakly Cemented Sandstones}

2.1. Deformation Mechanism Analysis of Weakly Cemented Sandstones. With the availability of mass test data and similarity of stress-strain change trends in weakly cemented 


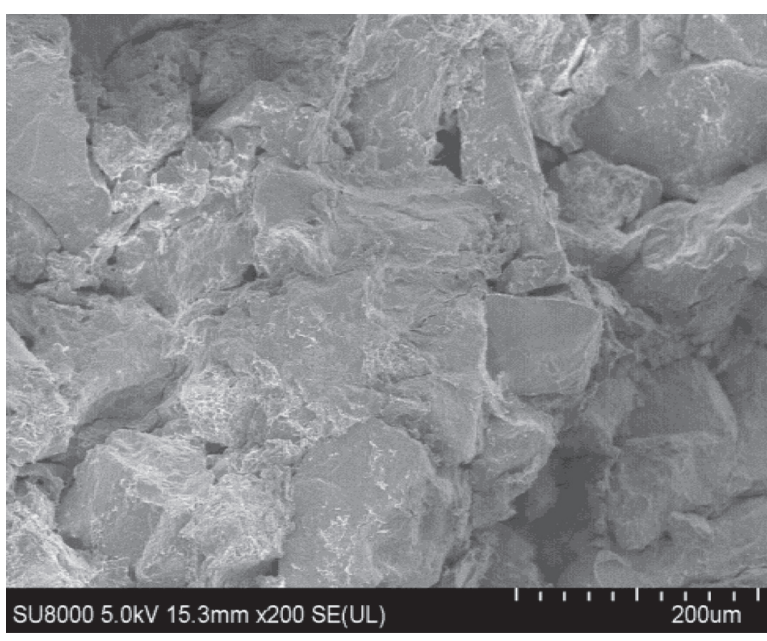

(a)

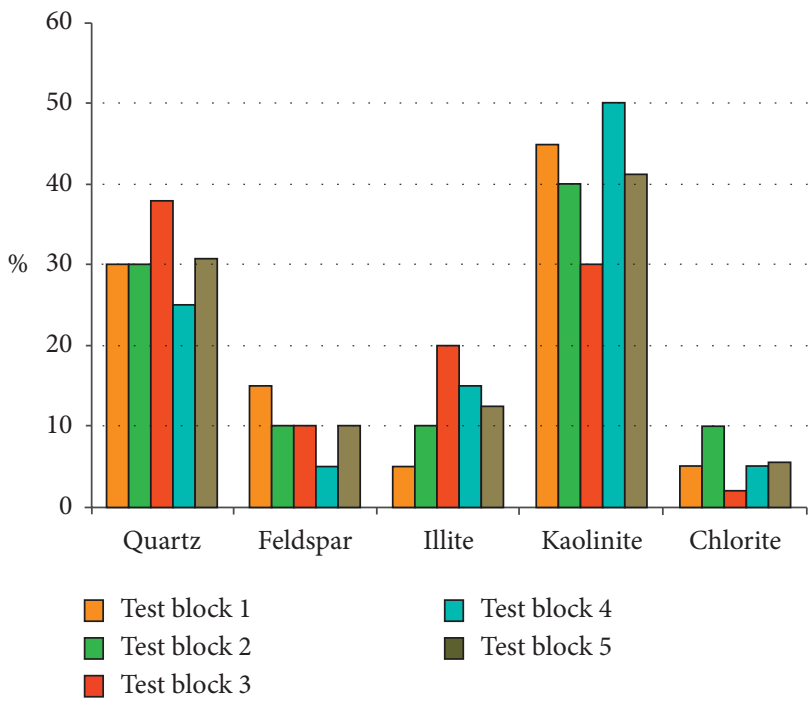

(c)

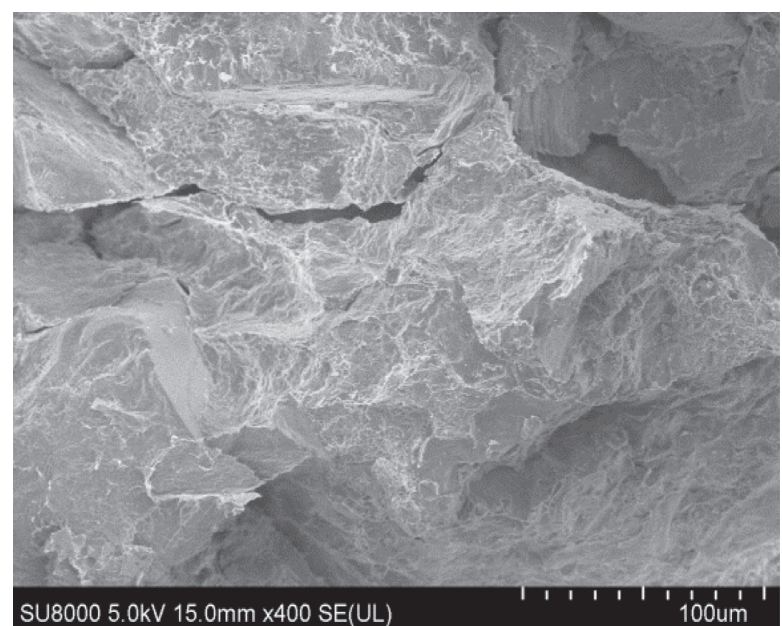

(b)

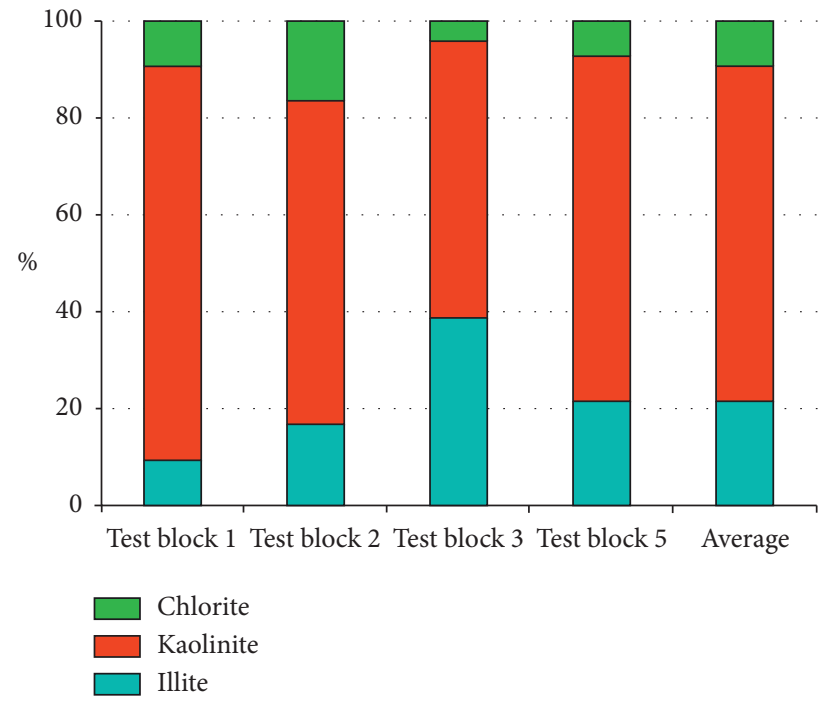

(d)

FIgURE 1: Microstructure and mineral component of rock: (a) $\times 200$ multiples, (b) $\times 400$ multiples, (c) XRD mineral composition, and (d) histogram of clay mineral composition accumulation.

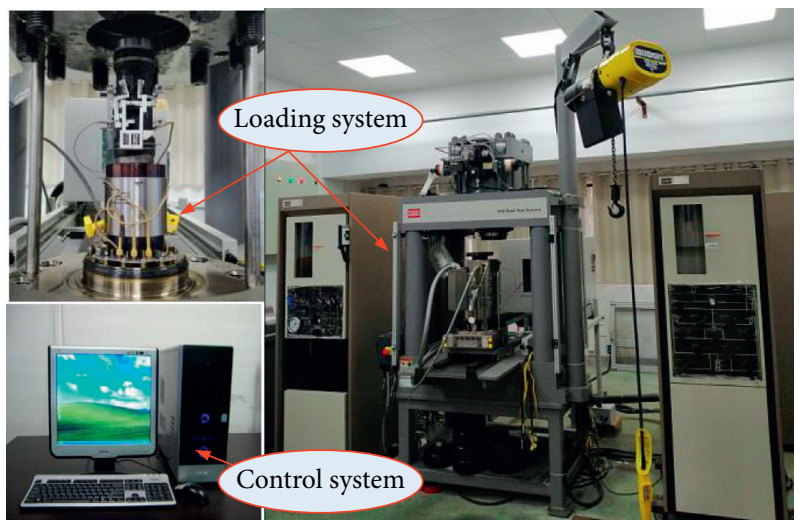

Figure 2: Test system of MTS816.

sandstones, only typical stress-strain curves are listed in Figure 3. As in most rock masses, the stress-strain curve of weakly cemented sandstone can be divided into five phases: compaction, elastic, plastic, strain-softening phase, and residual. The following results were obtained from the stressstrain curves.

The weakly cemented sandstones present type II unstable failure under confining pressures of 0,5 , and $10 \mathrm{MPa}$, and their deformation mechanisms were mainly circumferential and volume expansion. No sample experienced an obvious yield phase under low confining pressure, and as the confining pressure increased, the prepeak yield characteristic gradually strengthened. After the rock reached peak strength, the peak strength dropped rapidly until evident brittle failure [4]. When the confining pressure increased to $15 \mathrm{MPa}$, a section underwent a slow decline between peak strength and residual strength, the rock inclined toward ductile failure, and the failure mode of the weakly cemented sandstone shifted from type II unstable failure to type I stable failure.

In Figure 3(a), compared with the samples under confining pressures of $10 \mathrm{MPa}$ and $15 \mathrm{MPa}$, the compaction 

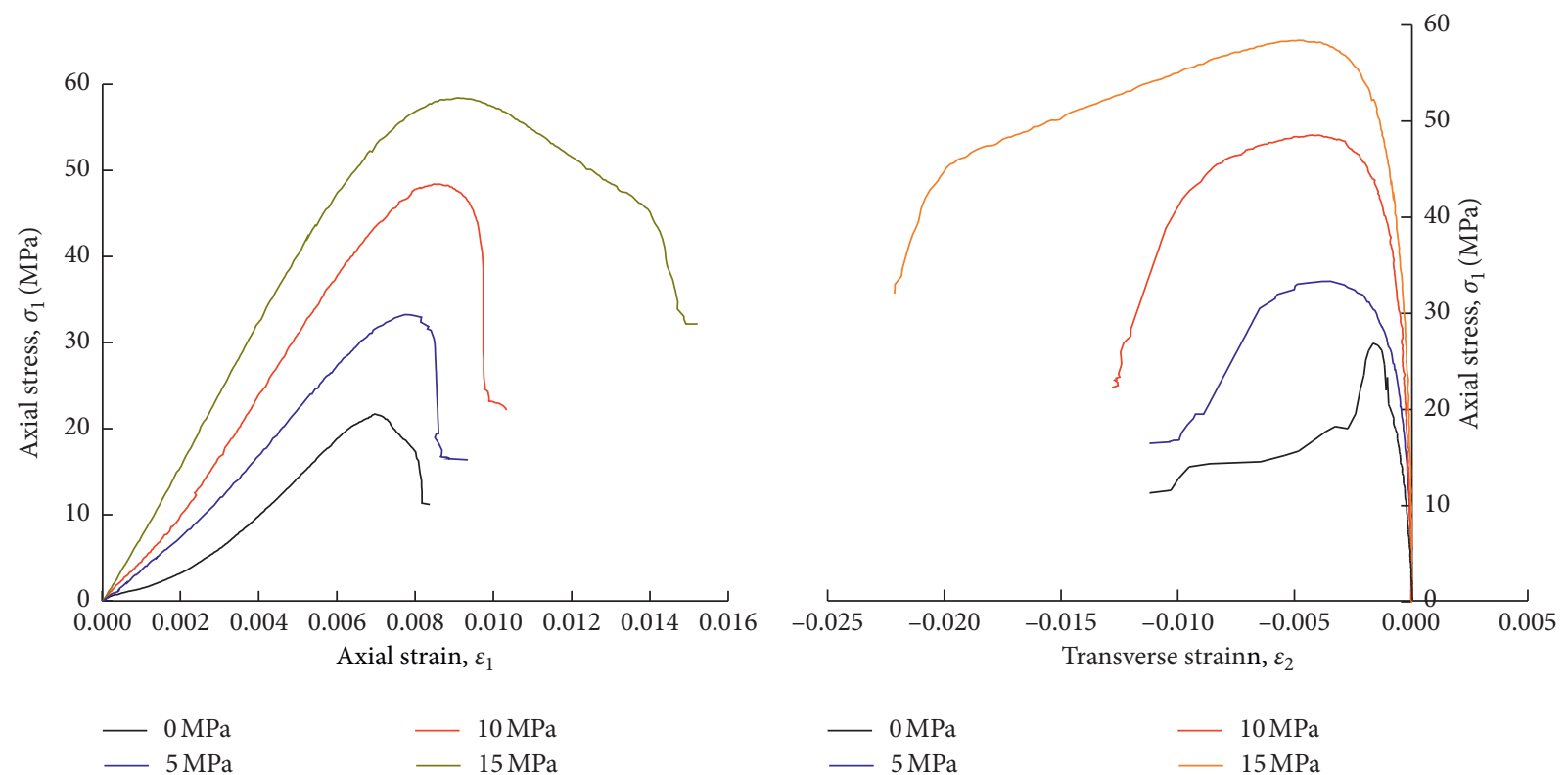

$-5 \mathrm{MPa}$

(b)

(a)

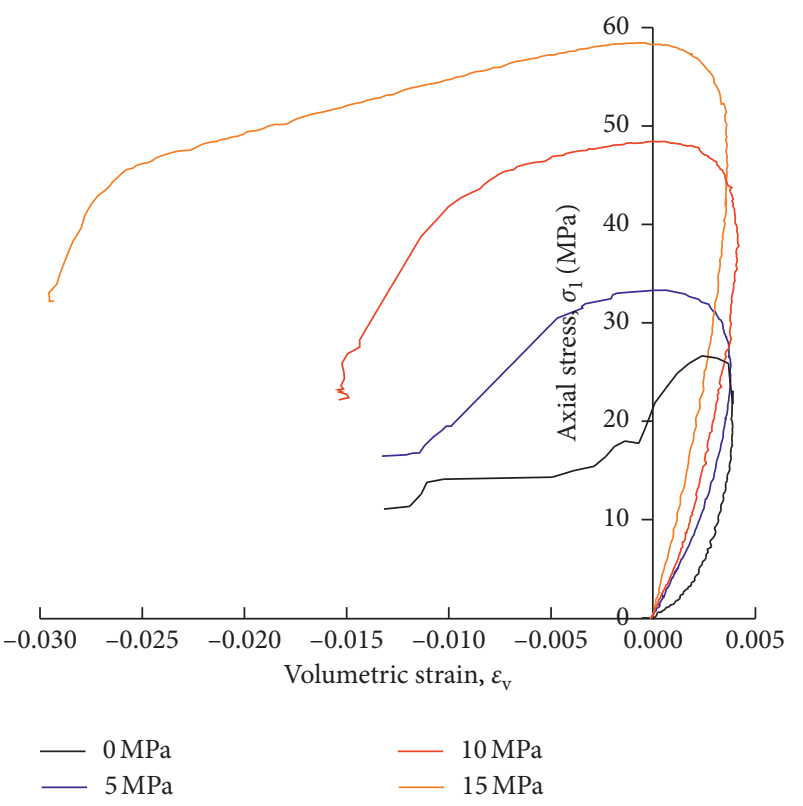

(c)

FiguRE 3: Stress-strain curves of weak cementation sandstone under different confining pressures: (a) axial stress curve, (b) transverse stress curve, and (c) volume stress curve.

phase of the sample under $5 \mathrm{MPa}$ was obvious because weakly cemented protogenetic fissures and voids were highly developed. Under low confining pressure, the hydrostatic loading phase was insufficient to complete the entire compaction process of jointed fissures. As the confining pressure grew, the compaction phase gradually shortened, an obvious yield phase occurred before the peak, the peak strain also gradually increased, and the peak strength point gradually moved backward; thus, the peak strength increased. These results indicated that the increasing confining pressure facilitated the closure of the intrinsic fissures of the sample, repressed fissure slippage, enhanced the ability to resist external force, and elevated the peak strength. As a result, the appearance of the compaction phase was less apparent.

As shown in Figures 3(b) and 3(c), as the confining pressure increased, the greater amplitude of circumferential strain was minor in the initial phase, and the volumetric strain presented an increasing trend. Under a small load, each rock sample was under a compression state, and the amount of compressive deformation was enlarged with the load increase. After the load reached the critical value, the curve underwent reversed bending, namely, the volume expansion phenomenon. As the stress reached a certain peak 
strength, the internal injury gradually started in the sample, and the microfissures continuously evolved, developed, and penetrated each other with the increase of stress. The volumetric strain was turned from the original decreasing direction into an increasing direction. The volumetric deformation was small before the peak stress, but it rapidly increased following the peak stress. Swelling deformation (dilatational deformation) of surrounding rocks induced by postpeak rupture of test block was the primary cause of large deformation of surrounding rocks on roadways and also the main support control object for these rocks. Moreover, this condition reflected the inhibiting effect of confining pressure on the dilatational deformation of rocks. As the confining pressure increased, the volumetric strain curve gradually became gentle after the peak or postpeak volume expansion characteristic gradually weakened. The lower the confining pressure, the greater the reduction amplitude of the circumferential and volumetric strains. According to the figure, the reduction amplitudes under $5 \mathrm{MPa}$ and $10 \mathrm{MPa}$ were obviously greater than those under $15 \mathrm{MPa}$. The inhibiting effect of confining pressure on the dilatational deformation of rocks was important to roadway support, indicating that, after the rupture of surrounding rocks in roadways, a suitable supporting force can contribute to improved control of deformation and failure of the surrounding rocks.

\subsection{Mechanical Properties under Different Confining} Pressures. Based on the stress-strain curves of the weakly cemented sandstones under various confining pressures, the development laws of the curves were largely identical before the peak value. In the initial loading phase, the original voids and microcracks were gradually compacted and closed, and the curve exhibited a depression. After the weakly cemented sandstone entered the linear elastic zone, its elasticity modulus $E$ and Poisson's ratio $\lambda$ were solved using formulas (1) and (2) through 3D Hooke's law.

$$
\begin{aligned}
& \lambda=\frac{\sigma_{3} \varepsilon_{1}-\sigma_{1} \varepsilon_{3}}{\left(\sigma_{1}+\sigma_{3}\right) \varepsilon_{1}-2 \sigma_{3} \varepsilon_{3}}, \\
& E=\frac{\sigma_{1}-2 \lambda \sigma_{3}}{\varepsilon_{1}} .
\end{aligned}
$$

The relationships between confining pressure and rock mechanical parameters are calculated as shown in Table 1.

According to Table 1, the elasticity modulus of the weakly cemented sandstone increased and Poisson's ratio decreased with the increase of confining pressure. As the confining pressure increased, the peak stress slowly grew, and its variation sensitivity was gradually degraded. An analysis showed that, under low confining pressure, the intercrystalline cementing action was the deciding factor in rock strength. As the confining pressure increased, the load borne by the rock was borne by intercrystalline slipping action, and the rock strength was related to frictional force. The bearing capacity of residual strength was mainly provided by the frictional force between rupture planes, and the slope of its stress-strain curve was approximately 0 [16]. Similar to the peak strength, the residual strength presented a rising trend with the increase of confining pressure. Under low confining pressure, the ratio of residual strength to peak strength was high. For instance, the residual strength accounted for $50.5 \%$ of the peak strength under $5 \mathrm{MPa}$. As the confining pressure increased, the ratio gradually reduced and tended to stabilize at approximately $48 \%$. For example, this ratio was $47.9 \%$ under $10 \mathrm{MPa}$ and became $48.07 \%$ under $15 \mathrm{MPa}$. The reason was that, under low confining pressure, the roughness of the rupture plane of weakly cemented sandstone was high with great irregularity, and the residual strength was enhanced due to low confining pressure and small strain [12]. This condition indicates that, after the rocks on the roadway experience failure, maintaining a certain confining pressure can obtain a considerable residual bearing capacity, which continues to provide a supporting force for the roadway.

\subsection{Failure Modes of Rock Samples}

2.3.1. Macroscopic Failure Characteristics. The macroscopic failure modes of weakly cemented sandstone under different confining pressures are shown in Figure 4. The rock mainly bore the tensile stress failure under conventional uniaxial compression condition. Many axial cracks were observed on the sample surface, the cracks were mainly types II and $X$ splitting forms, small sample blocks at two ends were peeled off, and no abrasion mark was found on the rupture plane. During the transformation process from low to high pressure in the conventional triaxial test, the rock failure gradually transited from tensile failure to tensile shear failure and pure shear failure. Under the joint action of shear failure and tensile failure during the loading process, the failure plane of the rock underwent tensile shear failure as shown in Figure 4(b). As the confining pressure increased, the rock mainly experienced shear failure and many grains were scattered in the shear zone as shown in Figures 4(c) and 4(d).

\subsubsection{Relationship between Confining Pressure and Rupture} Angle. The failure characteristics of weakly cemented sandstone varied with confining pressure, where the sandstone mainly experienced tensile shear failure under low confining pressure and the failure plane was relatively complex. As the confining pressure increased, the failure mode tended to be simple and a single shear plane appeared, mainly because the weakly cemented sandstone contained obvious mineral grains, the bonding strength between grains was low (weak cementation and bonding), and the failure generally presented a diagonal form. Most samples started cracking at one end. By examining the rupture angle in detail, we obtained the macroscopic failure characteristics of the weakly cemented sandstone.

In the triaxial test, $\tau$ has a linear relation with $\sigma$. Suzuki et al. $[17,18]$ proposed a double-parameter parabolic Mohr strength criterion expressed as follows:

$$
\sigma=a \tau^{2}+b
$$

where $a$ and $b$ are parameters. 
TABLE 1: Mechanical parameters of weak cementation sandstone.

\begin{tabular}{lcccccc}
\hline $\begin{array}{l}\text { Confining pressure } \\
(\mathrm{MPa})\end{array}$ & $\begin{array}{c}\text { Peak stress } \\
(\mathrm{MPa})\end{array}$ & $\begin{array}{c}\text { Peak strain } \\
(\%)\end{array}$ & $\begin{array}{c}\text { Residual strength } \\
(\mathrm{MPa})\end{array}$ & $\begin{array}{c}\text { Residual strength } \\
\text { point }(\%)\end{array}$ & $\begin{array}{c}\text { Modulus of elasticity } \\
(\mathrm{GPa})\end{array}$ & $\begin{array}{c}\text { Poisson's ratio } \\
0\end{array}$ \\
\hline 21.69 & 0.695 & 11.34 & 0.695 & 3.32 & 0.31 \\
5 & 33.35 & 0.772 & 16.80 & 0.772 & 4.45 & 0.29 \\
10 & 48.43 & 0.847 & 23.20 & 0.859 & 0.17 & 0.27 \\
15 & 58.48 & 0.905 & 28.07 & 0.905 & 0.22 \\
\hline
\end{tabular}
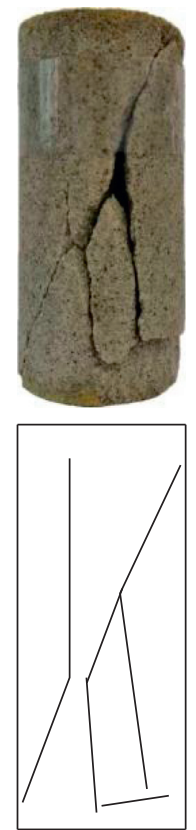

(a)
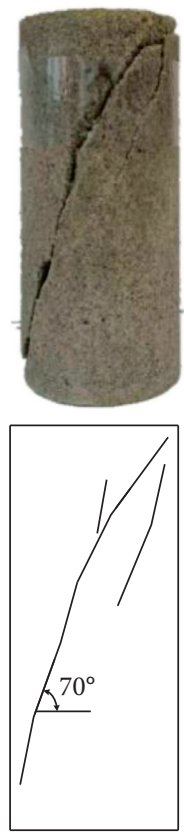

(b)
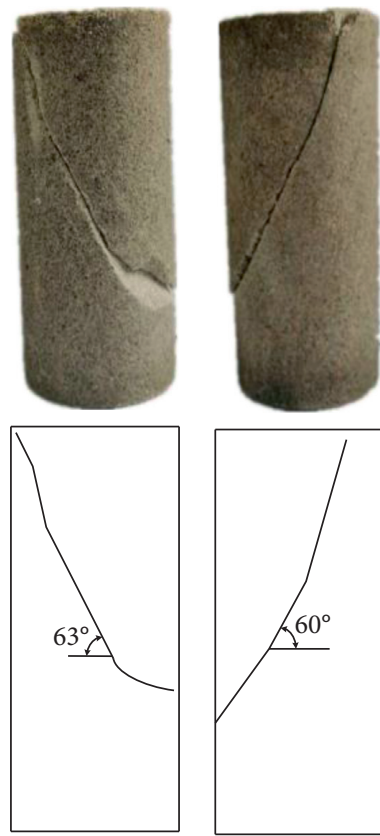

(c)

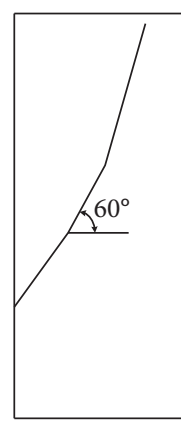

(d)

FIGURE 4: Failure characteristics of typical specimens with different confining pressures: (a) $0 \mathrm{MPa}$, (b) $5 \mathrm{MPa}$, (c) $10 \mathrm{MPa}$, and (d) $15 \mathrm{MPa}$.

Figure 5 presents the relationship between the doubleparameter parabolic strength curve and stress circle. $R_{t}$ is tensile strength, $R_{c}$ is compressive strength, and $m=R_{c} / R_{t}$ is the ratio of compressive strength to tensile strength. The following can be solved through parameters $a$ and $b$ :

$$
\begin{aligned}
& b=-R_{t}, \\
& a=\left(\frac{1+\sqrt{m+1}}{m}\right)^{2}\left(\frac{1}{R_{t}}\right) .
\end{aligned}
$$

Considering the relationship between principal stresses, $\mathrm{Li}[19]$ obtained the following results.

The parabolic principal stress relation curves within different stress ranges are obtained according to equation (4). In Figure 6, $\sigma_{1}=-R_{t}+(1 / a)$ is critical principal stress under which the test block experiences the change of failure mode, namely, from tensile failure to shear failure.

In the triaxial test, the failure laws of the rupture angle of the test block under different confining pressures are discussed. The following can be obtained according to the relationship between rupture and frictional angles in the Mohr strength criterion:

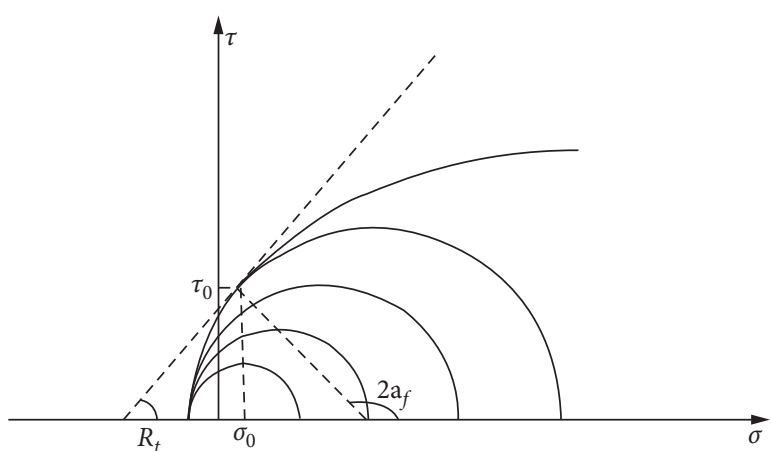

FIGURE 5: Double-parameter parabolic strength curve and stress circle.

$$
a_{f}=\left(\frac{\phi}{2}\right)+\left(\frac{\pi}{4}\right) \text {, }
$$

where $a_{f}$ is the rupture angle between the rupture and action planes of maximum principal stress. When $\sigma_{3}>-R_{t}$, the radius of the stress circle is $\left(\sigma_{1}-\sigma_{3}\right) / 2$, and the following is solved: 


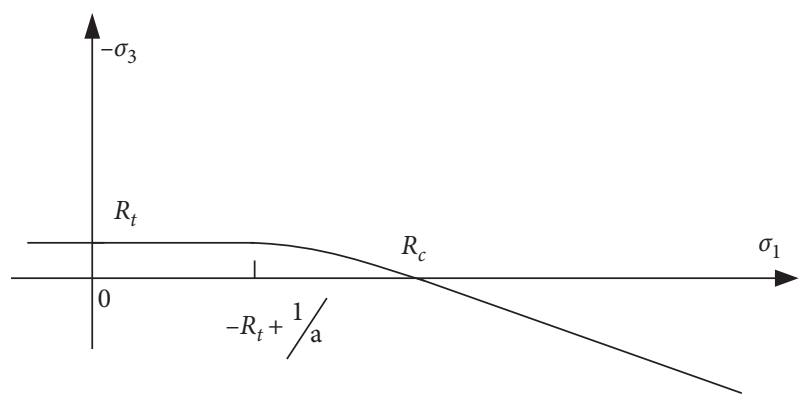

FIgURE 6: The relation curve of primary stress.

$$
\phi=\arccos \left(\frac{2 \tau_{0}}{\sigma_{1}-\sigma_{3}}\right) .
$$

In Figure 6, the distance from any point in the doubleparameter parabola to the center of the circle is

$$
d^{2}=\left(\sigma-\left(\frac{\sigma_{1}+\sigma_{3}}{2}\right)\right)^{2}+\tau^{2}
$$

Equation (3) is substituted into equation (8) and the derivative of $\tau$ is solved as follows:

$$
4 \tau a\left(a \tau^{2}-R_{t}-\left(\frac{\sigma_{1}+\sigma_{3}}{2}\right)\right)+2 \tau=0,
$$

to obtain

$$
\left\{\begin{array}{l}
\tau_{0}=0, \\
\sigma_{0}=-R_{t},
\end{array}\right.
$$

or

$$
\left\{\begin{array}{l}
\tau_{0}^{2}=\left(\frac{\sigma_{1}+\sigma_{3}}{2 a}\right)+\left(\frac{R_{t}}{a}\right)-\left(\frac{1}{2 a^{2}}\right), \\
\sigma_{0}=\left(\frac{\sigma_{1}+\sigma_{3}}{2}\right)-\left(\frac{1}{2 a}\right) .
\end{array}\right.
$$

Equations (10) and (11) are two points of tangency on the vertex and upper and lower planes of the double-parameter parabola where the parabola intersects with the stress circle.

Equations (10) and (21) are substituted into equations (6) and (7) to obtain the following:

$$
a_{f}=\left\{\begin{array}{l}
\frac{\pi}{2}, \quad\left(\left(\sigma_{3}=-R_{t}\right) \text { or }\left(-R_{t}<\sigma_{1} \leq-R_{t}+\left(\frac{1}{a}\right)\right)\right), \\
\left(\frac{\pi}{4}\right)+\left(\frac{1}{2}\right) \arccos \left(\frac{2 \sqrt{\left(\sigma_{1}+\sigma_{3} / 2 a\right)+\left(R_{t} / a\right)-\left(1 / 2 a^{2}\right)}}{\sigma_{1}-\sigma_{3}}\right), \\
\left(\left(\sigma_{3}>-R_{t}\right) \text { or }\left(\sigma_{1}>-R_{t}+\left(\frac{1}{a}\right)\right)\right) .
\end{array}\right.
$$

The rupture angle was $\pi / 2$ when and only when the rock was under tensile failure mode. According to limit analysis, as the confining pressure increased, $a_{f}$ gradually declined, the declining trend became mild, and the rupture angle finally tended to be $\pi / 4$. The change of the rupture angle manifested that the influence degree of normal stress on the resisting frictional force was continuously changing under different stress states. As shown in Figure 4, the rupture angles under 5,10 , and $15 \mathrm{MPa}$ were $70^{\circ}, 63^{\circ}$, and $60^{\circ}$, respectively. The macroscopic failure characteristics of the test block under different confining pressures were consistent with the preceding theoretical analysis.

\section{Constitutive Damage Model of Weakly Cemented Sandstone}

3.1. Model Construction. We assume that the weakly cemented rock follows Weibull distribution, and then the function of its probability density distribution [19] is as follows:

$$
P(F)=\left(\frac{a}{F_{0}}\right)\left(\frac{F}{F_{0}}\right)^{a-1} \exp \left[-\left(\frac{F}{F_{0}}\right)^{a}\right],
$$

where $a$ and $F_{0}$ are the Weibull distribution parameters.

According to the strain equivalence theory proposed by Lematire [20] and the concept of effective stress, the relationships of damage variable $D$ with nominal stress $\sigma$ and effective stress $\sigma^{*}$ are as follows:

$$
\sigma^{*}=\left(\frac{\sigma}{1-D}\right) \text {. }
$$

In the triaxial test, a certain residual strength exists under the influence of confining pressure. The slope of the stressstrain curve is approximately 0 and the curve is approximate to a horizontal straight line. In consideration of postpeak residual strength, as the residual strength continued to transfer partial shear stress and compressive stress, the correction coefficient $\eta$ for the damage variable was introduced and defined as follows:

$$
\eta=\sqrt{\left(\frac{\sigma_{c c}}{\sigma_{1 c}}\right)}
$$

where $\sigma_{1 c}$ is the peak strength and $\sigma_{c c}$ is the residual strength.

The relationship between nominal stress and effective stress after correction is

$$
\sigma^{*}=\left(\frac{\sigma}{1-D \eta}\right)
$$

The relation between the damage variable and the probability density of infinitesimal damage is as follows:

$$
D=\int_{0}^{f\left(\sigma^{*}\right)} P\left[f\left(\sigma^{*}\right) \mathrm{d} x\right] .
$$

Equation (13) is substituted into equation (17) to obtain

$$
D=1-\exp \left[-\left(\frac{F}{F_{0}}\right)^{a}\right] \text {. }
$$

According to generalized Hooke's law, equation (16) is substituted into equation (18), and the statistical model of 
rock damage softening under $3 \mathrm{D}$ stress is obtained as follows:

$$
\sigma_{1}=E \varepsilon_{1}\left[1-\eta+\eta \exp \left[-\left(\frac{F}{F_{0}}\right)^{a}\right]\right]+\lambda\left(\sigma_{2}+\sigma_{3}\right)
$$

where $\sigma_{1}$ is the maximum principal stress, $\sigma_{2}$ and $\sigma_{3}$ are the confining pressures, $\varepsilon_{1}$ is the strain in the direction of maximum principal stress, $E$ is the elasticity modulus, $\lambda$ is Poisson's ratio, and $a$ and $F_{0}$ are the Weibull distribution parameters.

Hoek-Brown criterion [21] expressed by effective stress invariant is

$$
\begin{aligned}
& f\left(\sigma^{*}\right)=m \sigma_{c}\left(\frac{I_{1}^{*}}{3}\right)+4 J_{2}^{*} \cos \theta_{\sigma}+m \sigma_{c} \sqrt{J_{2}^{*}}\left(\cos \theta_{\sigma}+\left(\frac{\sin \theta_{\sigma}}{\sqrt{3}}\right)\right)=s \sigma_{c}^{2}, \\
& I_{1}^{*}=\left(\sigma_{1}^{*}+\sigma_{2}^{*}+\sigma_{3}^{*}\right) \\
& J_{2}^{*}=\left(\frac{1}{6}\right)\left[\left(\sigma_{1}^{*}-\sigma_{2}^{*}\right)+\left(\sigma_{1}^{*}-\sigma_{3}^{*}\right)+\left(\sigma_{2}^{*}-\sigma_{3}^{*}\right)\right]
\end{aligned}
$$

where $I_{1}^{*}$ and $J_{2}^{*}$ are the first invariant of effective stress and second invariant of deviator of effective stress and $\theta_{\sigma}$ is the Lode angle.

In the conventional triaxial test, $\sigma_{1}>\sigma_{2}=\sigma_{3}, \theta_{\sigma}=30^{\circ}$ is substituted into equation (20) to obtain

$$
f\left(\sigma^{*}\right)=m \sigma_{c}\left(\frac{I_{1}^{*}}{3}\right)+3 J_{2}^{*}+\left(\frac{2}{3}\right) m \sigma_{c} \sqrt{J_{2}^{*}} \cos \theta_{\sigma}=s \sigma_{c}^{2} .
$$

We assume that infinitesimal failure follows the HoekBrown criterion, and $f\left(\sigma^{*}\right)$ is selected as a random distribution variable of rock infinitesimal strength and substituted into equation (19) according to generalized Hooke's law [22] to obtain

$$
E \varepsilon_{1}\left\{(1-\eta)+\eta \exp \left[-\left(\frac{m \sigma_{c} \sigma_{1} E \varepsilon_{1}}{F_{0}\left(\sigma_{1}-2 \lambda \sigma_{3}\right)}\right)+\left(\frac{\left(E \varepsilon_{1}\left(\sigma_{1}-\sigma_{3}\right)\right)^{2}}{F_{0}\left(\sigma_{1}-2 \lambda \sigma_{3}\right)^{2}}\right)^{a}\right]\right\}+2 \lambda \sigma_{3}
$$

where $\sigma_{1}$ is the maximum principal stress, $\sigma_{2}$ and $\sigma_{3}$ are the confining pressures, $\varepsilon_{1}$ is the strain in the direction of maximum principal stress, $E$ is the elasticity modulus, $\lambda$ is Poisson's ratio, and $a$ and $F_{0}$ are the Weibull distribution parameters.

3.2. Parameter Determination. A total of six parameters, namely, $F_{0}, \alpha, E, \lambda, m$, and $\sigma_{c}$, are included in the statistical constitutive equation of $3 \mathrm{D}$ stress, which is obtained based on Hoek-Brown strength criterion, where $E$ and $\lambda$ can be obtained through the triaxial test, and $m$ and $\sigma_{c}$ are obtained according to Hoek-Brown strength criterion, which can explain the influences of low-stress zone, tensile stress zone, and minimum principal stress on rock strength.

The expression is

$$
\sigma_{1}=\sigma_{3}+\sigma_{c} \sqrt{m_{i}\left(\frac{\sigma_{3}}{\sigma_{1}}\right)+s}
$$

where $\sigma_{c}$ is the uniaxial compressive strength and $m$ and $s$ are the empirical parameters.

The triaxial compression results of the weakly cemented rock are fitted according to the Hoek-Brown strength criterion, and the fitting formula is

$$
\sigma_{1}=\sigma_{3}+21.69 \sqrt{4.42\left(\frac{\sigma_{3}}{\sigma_{1}}\right)+0.94}\left(\mathrm{R}^{2}=0.983\right) \text {. }
$$

$\sigma_{c}=21.69$ and $m=4.42$ can be obtained through fitting.

$\alpha$ and $F_{0}$ are the keys to establishing the constitutive model. According to the rock failure stress-strain curve, the peak stress is $\sigma_{1 c}$, and the following boundary conditions can be obtained: 
TABLE 2: Weibull distribution model parameters.

\begin{tabular}{lcccccccc}
\hline Serial number of rock sample & $\sigma_{3}(\mathrm{MPa})$ & $E(\mathrm{GPa})$ & $\sigma_{1 c}(\mathrm{MPa})$ & $\varepsilon_{1}(\%)$ & $\lambda$ & $\eta$ & $a$ & $F_{0}$ \\
\hline 1 & 0 & 4.67 & 21.69 & 0.695 & 0.31 & 0.52 & 13.96 & 3191.2 \\
2 & 5 & 5.12 & 33.35 & 0.772 & 0.29 & 0.50 & 7.28 & 5584.4 \\
3 & 10 & 6.32 & 48.43 & 0.847 & 0.27 & 0.48 & 4.37 & 9334.1 \\
4 & 15 & 6.54 & 58.48 & 0.905 & 0.22 & 0.47 & 3.08 & 11937.1 \\
\hline
\end{tabular}

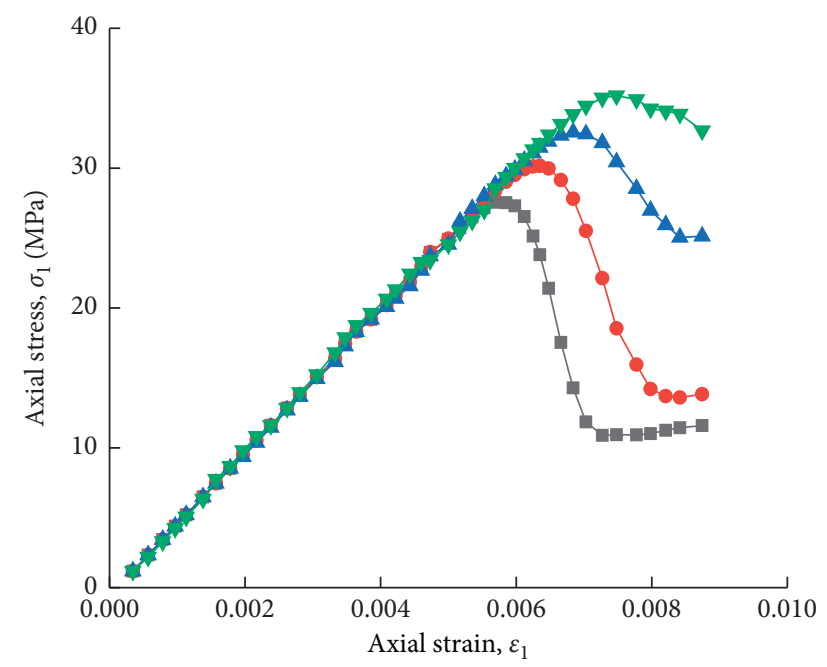

$\begin{array}{ll}\longrightarrow F 0=3800 & \longrightarrow F 0=5800 \\ \longrightarrow F 0=4800 & \longrightarrow F 0=6800\end{array}$

(a)

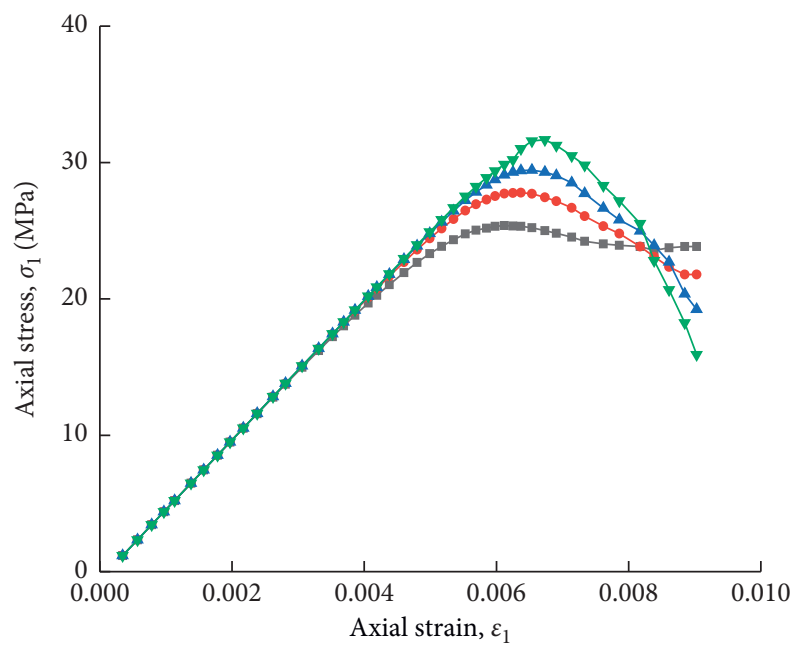

$\rightarrow-a=2$

$\rightarrow a=3$

$-a=4$

(b)

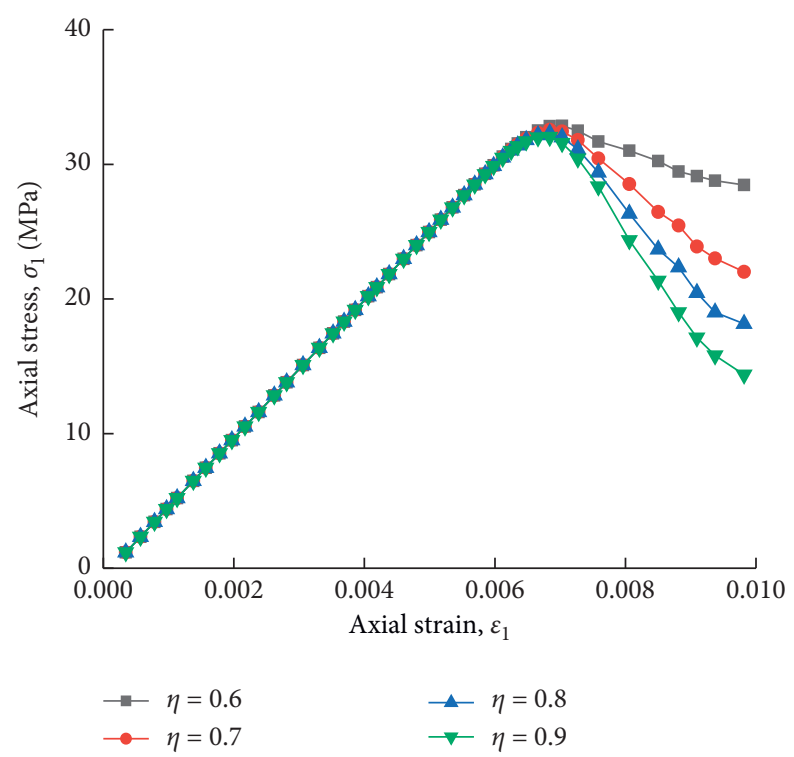

(c)

FiguRE 7: The curve of stress-strain of rock specimen and correction factor under different Weibull distribution parameters: (a) different parameters $F_{0}$, (b) different parameters $a$, and (c) different correction factors $\eta$. 

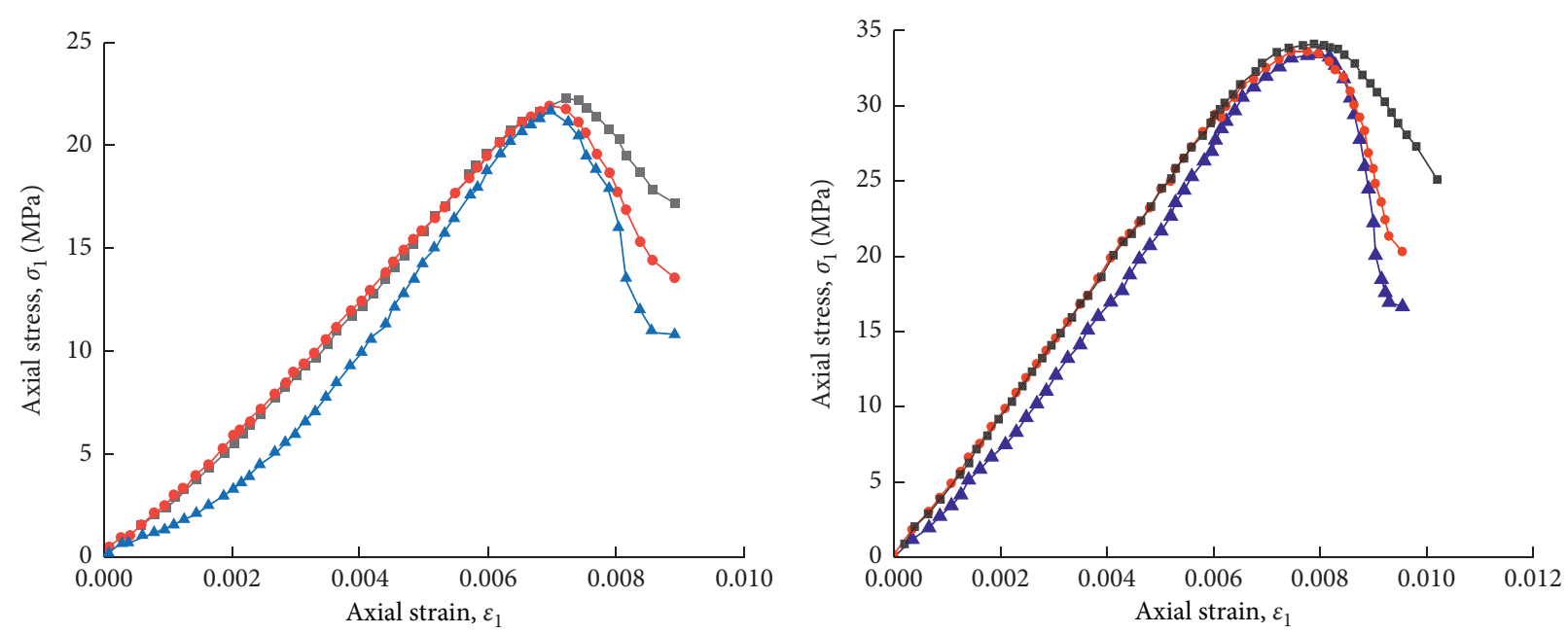

- Theoretical curve (without correction)

- Theoretical curve (correction)

$=$ Theoretical curve (without correction)

$\rightarrow$ Theoretical curve (correction)

$\leadsto$ Test curve

$\_$Test curve

(a)

(b)
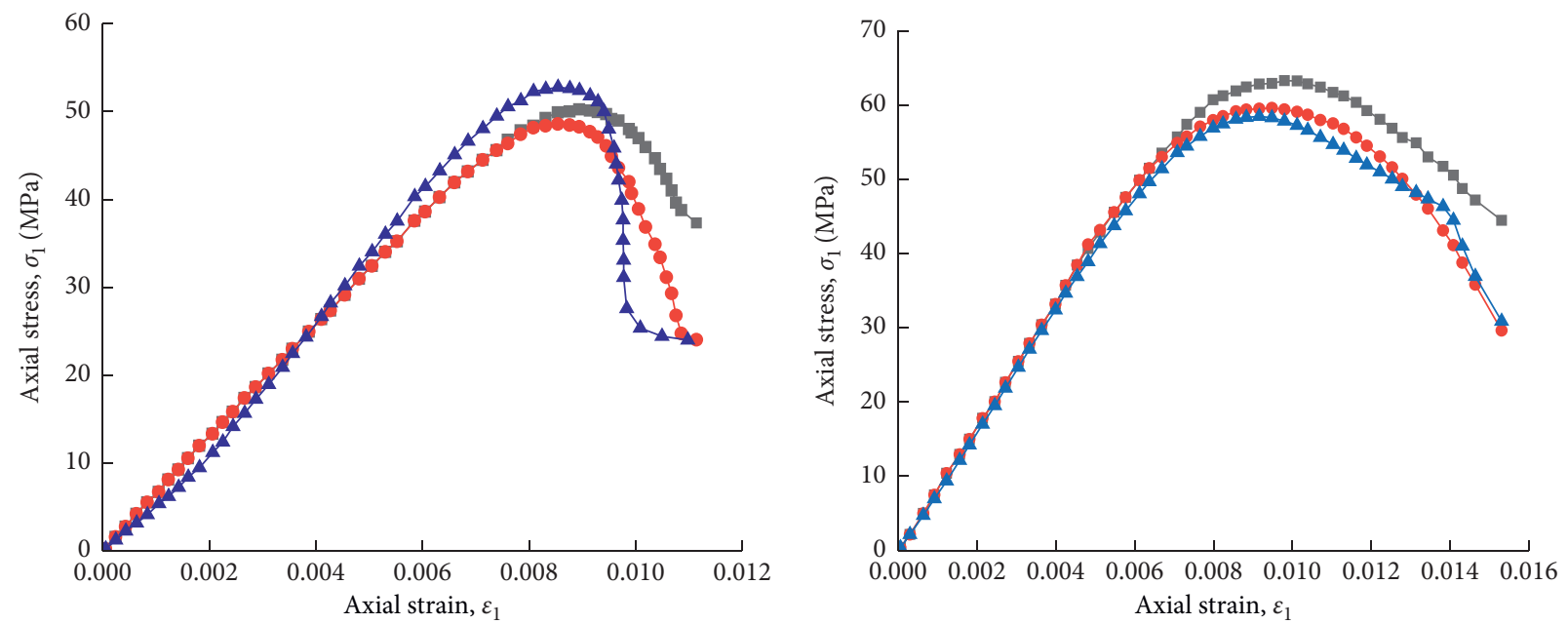

$=$ Theoretical curve (without correction)

$\rightarrow$ Theoretical curve (correction)

$\_$Test curve

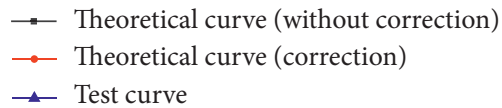

(d)

FIgURE 8: The curve of test pressure and date fitting under different confining pressures: (a) confining pressure $0 \mathrm{MPa}$, (b) confining pressure $5 \mathrm{MPa}$, (c) confining pressure $100 \mathrm{MPa}$, and (d) confining pressure $15 \mathrm{MPa}$.

$$
\left.\begin{array}{ll}
\varepsilon=0, & \sigma=0, \\
\varepsilon=0, & \frac{d \sigma}{d \varepsilon}=0, \\
\varepsilon=\varepsilon_{1 c}, & \sigma=\sigma_{1 c}, \\
\frac{d \sigma_{1}}{d \varepsilon_{1}}=0, & \sigma=\sigma_{1 c} .
\end{array}\right\}
$$

The derivative of equation (25) is solved, and the boundary conditions of equation (22) are substituted to obtain

$$
\begin{aligned}
a= & \left(\frac{\left(\sigma_{1 c}-2 \lambda \sigma_{3} / E \varepsilon_{1 c}\right) \times F}{\varepsilon_{1 c}\left(\left(\sigma_{1 c}-2 \lambda \sigma_{3}\right)+\left(\eta E \varepsilon_{1 c}-E \varepsilon_{1 c} / E \varepsilon_{1 c}\right)\left(\partial F / \partial \varepsilon_{1}\right)\right.}\right) \\
& \times\left(\frac{1}{\left(-\ln \left(\left(\sigma_{1 c}-2 \lambda \sigma_{3}\right)+\left(\eta E \varepsilon_{1 c}-E \varepsilon_{1 c}\right) / \eta E \varepsilon_{1 c}\right)\right.}\right), \\
F_{0}= & {\left[\frac{F_{c}^{a}}{-\ln \left(\left(\sigma_{1 c}-2 \lambda \sigma_{3}\right)+\left(\eta E \varepsilon_{1 c}-E \varepsilon_{1 c}\right) / \eta E \varepsilon_{1 c}\right)}\right]^{(1 / a)}, }
\end{aligned}
$$

where 


$$
\begin{gathered}
\mathrm{F}=\left(\frac{m \sigma_{c} \sigma_{1} E \varepsilon_{1}}{\sigma_{1 c}-2 \lambda \sigma_{3}}\right)+\left(\frac{\left(E \varepsilon_{1}\left(\sigma_{1}-\sigma_{3}\right)\right)^{2}}{\left(\sigma_{1 c}-2 \lambda \sigma_{3}\right)^{2}}\right), \\
\frac{\partial F}{\partial \varepsilon_{1}}=\left(\frac{m \sigma_{c} \sigma_{1} E}{\sigma_{1 c}-2 \lambda \sigma_{3}}\right)+\left(\frac{2\left(E \varepsilon_{1}\left(\sigma_{1}-\sigma_{3}\right)\right)^{2}}{\left(\sigma_{1 c}-2 \lambda \sigma_{3}\right)^{2}}\right) .
\end{gathered}
$$

3.3. Discussion and Correction of Model Parameters. The statistical model of rock damage was established based on the Hoek-Brown criterion. The accuracy of the model was verified through the triaxial test data under different confining pressures, and the parameters of the constitutive model are shown in Table 2.

$F_{0}$ and $a$ of Weibull random distribution influence the stress-strain curve shape and geometric distribution. When the confining pressure was $5 \mathrm{MPa}$ while other conditions were unchanged, $F_{0}$ and $\alpha$ were used as variables to draw the stress-strain curves of the rock samples $\left(F_{0}=5584.4\right.$ and $\alpha=7.28)$. Figure 7 shows the stress-strain curves under different damage correction coefficients $\eta$ when the other parameters are unchanged.

As shown in Figure 7, in the prepeak initial phase of the stress-strain curve, the parameter influence on the curve shape was minor. As the $F_{0}$ and $a$ values increased, they had a strong effect on the curve in the postpeak softening phase. When $F_{0}$ increased, the overall curve moved backward and upward, and the peak strength and residual strength were increased. $F_{0}$ mainly reflects the macrostatistical average rock strength and a mainly characterizes rock brittle strength and infinitesimal strength distribution in different rocks. The correction coefficient $\eta$ was introduced, the prepeak curve changed minimally while the sensitivity of the residual strength was aggravated, which mainly reflected the residual strength of the rock.

3.4. Model Verification. $F_{0}, \alpha, m$, and $\sigma_{c}$ obtained through data fitting and test parameters were substituted into the proposed constitutive equation to obtain its stress-strain (corrected) and test curves, which were compared with the uncorrected theoretical curve mentioned by literature [21] to verify the reliability of the constitutive model of weakly cemented sandstone as shown in Figure 8.

The constitutive model of $3 \mathrm{D}$ stress damage softening proposed in this paper reflected the entire influence process of stress state on the rock strength, and the test curve was in accordance with the model curve. As the nonlinear compaction of the material itself was not considered by the constructed damage softening model in the initial phase, a certain difference existed in the initial compaction phase, which should be highlighted in follow-up studies. After the peak strength, the gap between the theoretical and test curves was expanded. In view of postpeak residual strength, the correction coefficient for the damage variable was introduced, and then the theoretical curve had higher goodness of fit with the test curve.

\section{Conclusion}

(1) The rock microstructure was observed through SEM. The cement contained in this rock is clay minerals with poor rounding and separation properties. According to XRD analysis, the man mineral components were quartz, feldspar, illite, kaolinite, and chlorite.

(2) The weakly cemented sandstone was identical with most rock masses, and its stress-strain curve was divided into five phases: compaction, elastic, plastic, strain-softening, and residual. After the rock reached peak strength, the peak strength rapidly dropped and the rock underwent evident brittle failure. Under high confining pressure, a slow decrease occurred between peak and residual strengths, and the rock tended toward ductile failure.

(3) In the triaxial compression test, the peak strength, residual strength, and elasticity modulus increased with the increase of confining pressure, indicating that after the roadway experienced a failure, maintaining a certain confining pressure could acquire considerable residual bearing capacity and continue to provide a certain supporting force for the roadway.

(4) Under different confining pressures, the macroscopic failure characteristics of the various rock samples were different. The failure mode under low confining pressure was mainly tensile shear failure. As the confining pressure increased, the failure mode centered on the shear failure. Based on the macroscopic failure characteristics, the relational equation between the rupture angle and confining pressure was established.

(5) The damage variable was calculated by combining the Weibull distribution based on the Hoek-Brown criterion. Considering the residual strength, we introduced the correction coefficient $\eta$ for the damage variable to construct a constitutive model of $3 \mathrm{D}$ stress damage softening. This constitutive model reflected the entire influence process of stress state on rock strength. We verified through comparison that the test curve had high goodness of fit with the constructed constitutive model curve.

\section{Data Availability}

Readers can access the data supporting the conclusions of the study. The nature of the data is the laboratory experimental data and the theoretical calculation data. The laboratory experimental data used to support the findings of this study are included within the article; mainly, the mechanical parameters used to support the findings of this study are available from the corresponding author upon request. The theoretical calculation data used to support the findings of this study are available from the corresponding author upon request. 


\section{Conflicts of Interest}

The authors declare no conflicts of interest.

\section{Authors' Contributions}

All authors contributed to the publication of this study. Wei Zou conceived and designed the experiments, Jinlong Cai performed the experiments, Wei Zou analyzed the data, Wei Zou revised and reviewed the manuscript, and Jinlong Cai wrote the corresponding paper.

\section{Acknowledgments}

This study was part of the projects financially supported by the Chinese National Natural Science Foundation (NSFC, Grants nos. 51574007 and 51604007). The authors gratefully acknowledge the financial support received from NSFC.

\section{References}

[1] W. M. Wang, Z. H. Zhao, and L. Wang, "Elastic-plastic damage analysis for weakly consolidated surrounding rock regarding stiffness and strength cracking," Chin. J Min Saf Eng.vol. 30, pp. 680-685, 2013.

[2] W. M. Wang, L. Wang, and C. Q. Dai, "Frozen wall deformation analysis in weakly cemented soft rock based on layered calculation of strength," Journal of Rock Mechanics and Geotechnical Engineering, vol. 30, pp. 4110-4116, 2011.

[3] H. M. Li, K. L. Wang, and C. Liu, "Study on mechanical and acoustic emission characteristics of weakly cementation sandstone in Shendong coal field," J Min Saf Eng, vol. 35, pp. 844-850, 2018.

[4] Z. H. Chen, C. He, and W. J. Dong, "Physico-mechanical properties and its energy damage evolution mechanism of the Jurassic and Cretaceous argillaceous sandstone in Northern Xinjiang," Journal of Rock Mechanics and Geotechnical Engineering, vol. 29, pp. 2874-2884, 2018.

[5] Z. Y. Song, H. G. Ji, and Z. H. Liu, "Morphology and failure mechanism of the shear fracture surface of weakly cemented sandstone with water saturation," Journal of China Coal Society, vol. 43, pp. 2444-2451, 2018.

[6] Z. Y. Song and F. B. Ning, "Progress on the association between mesostructural parameters and macromechanical behaviors of weakly cemented," Journal of Rock Mechanics and Geotechnical Engineering, vol. 12, pp. 1-9, 2018.

[7] L. H. Sun, H. G. Ji, and B. S. Yang, "Physical and mechanical characteristic of rocks with weakly cemented strata in Western representative mining area," Journal of China Coal Society, vol. 44, pp. 865-873, 2019.

[8] Q. H. Li, J. Hou, and M. Y. Wang, "Experimental investigations on mechanical characteristics of weakly cemented sandy mudstone under progressive failure," Journal of Rock Mechanics and Geotechnical Engineering, vol. 41, pp. 385-392, 2016.

[9] H. Wang, T. H. Yang, and T. Xu, "Acoustic emission characteristics and failure patterns of a weak cemented sandstone under uniaxial compression: Xiaojihan coal mine in Shanxi as a case," Journal of China Coal Society, vol. 43, pp. 39-45, 2014.

[10] H. G. Ji, B. Chen, and L. H. Sun, "Research on the acoustic emission of weakly consolidated sandstone under uniaxial compression in Hongqinghe coal mine," Journal of Rock
Mechanics and Geotechnical Engineering, vol. 44, pp. 56-61, 2015.

[11] H. Wang, T. H. Yang, and Q. L. Yu, "Constitutive relationship of the sandstone from Yuheng mining area under different confining pressures," Journal of China Coal Society, vol. 40, no. S2, pp. 320-327, 2015.

[12] Z. H. Zhao, W. M. Wang, and X. Gao, "Damage behavior of weakly consolidated soft mudstone under tri-axial compression," Journal of Zhejiang University Science B, vol. 48, pp. 1399-1405, 2014.

[13] Z. H. Zhao, Q. Ma, and X. J. Gao, "Non-synergistic deformation and catastrophic mechanism of surrounding rock of weakly cemented soft rock roadway," Chin. J Min Saf Eng.vol. 36, pp. 273-279, 2019.

[14] Q. B. Meng, L. J. Han, and H. Pu, "Research and monitoring analysis of coal roadway bolting system in very weakly cemented stratum," Journal of China Coal Society, vol. 41, pp. 234-245, 2016.

[15] Q. B. Meng, L. J. Han, and W. G. Qiao, "Elastic-plastic analysis of the very weakly cemented surrounding rock considering characteristics of strain softening and expansion," Journal of China University of Mining and Technology, vol. 47, pp. 234-245, 2016.

[16] D. Huang, q. TAn, and R. J. huANG, "Study of micromesoscopic characteristics of marble fracture surface and correlation with unloading rock mass strength under high stress and unloading," Rock Soil Mech, vol. 33, pp. 7-15, 2012.

[17] M. G. Ling, Rock Mass Mechanics and Test, China Coal Industry Publishing House, Beijing, China, 1980.

[18] C. G. Li, H. Zhen, and X. R. Ge, "Research on two-parameter parabolic Mohr strength criterion and its damage regularity," Journal of Rock Mechanics and Geotechnical Engineering, vol. 24, pp. 4428-4433, 2005, ).

[19] W. ., G. Cao, Z. L. Fang, and X. J. Tang, "A Study of statistical constitutive model for soft and damage rocks," Journal of Rock Mechanics and Geotechnical Engineering, vol. 17, pp. 628-633, 1998, ).

[20] J. Lemaitre, "A continuous damage mechanics model for ductile fracture," Journal of Engineering Materials and Technology, vol. 107, no. 1, pp. 83-89, 1985.

[21] Y. R. Zheng, Geotechnical Plastic Mechanics, China Architecture Publishing House, Beijing, China, 2002.

[22] W. G. Cao, H. Zhao, and X. Li, "A statistical damage simulation method for rock full deformation process with consideration of the deformation characteristics of residual strength phase," Journal of Rock Mechanics and Geotechnical Engineering, vol. 45, pp. 139-145, 2012. 